\title{
What are We Going to Do with Complete Responses After Chemoradiation of Rectal Cancer?
}

\author{
Geerard L. Beets, MD, PhD \\ Department of Surgery, Netherlands Cancer Institute, Amsterdam, The Netherlands
}

It doesn't matter if you think that a watch-and-wait policy for clinical complete responders is a dangerous development that jeopardizes the improvements in oncological outcome of the last decades or if you think that it is an exciting new development. Please read the paper by AlSukhni et al. in this issue of Annals of Surgical Oncology and take some time to absorb the number of 5512 patients in whom the pathologist did not find any residual tumor in the rectal resection specimen. ${ }^{1}$ In a large, nationwide, U.S. cancer database, estimated to capture $70 \%$ of patients treated from 2006-2011, this represents nearly one quarter of patients after chemoradiation. My last patient with a pathological complete response after a low anterior resection almost died in the intensive care unit and ended up with a definitive stoma and a complex incisional hernia. The morbidity, mortality, and long-term functional problems after major rectal cancer surgery used to be "all in the game" but are now becoming more difficult to justify in patients with a complete response. After the pioneering report by Angelita Habr-Gama from Sao Paulo in 2004 on a watch-and-wait strategy, there are now an increasing number of other positive reports. ${ }^{2}$ The oncological and surgical community initially responded with skepticism and disbelief, but last year several well-designed studies were accompanied by cautiously positive commentaries. ${ }^{3-8}$ A recurring theme is that we should try to identify complete responses and then discuss the alternative treatment options in a shared decision process, taking into account the individual patient's preferences. ${ }^{9}$

(C) Society of Surgical Oncology 2016

First Received: 15 February 2016;

Published Online: 8 March 2016

G. L. Beets, MD, PhD

e-mail: g.beets@nki.nl
Whereas the most striking element in the paper by AlSukhni is that it is hard to ignore the importance of the complete response issue in such a large group of patients, the official purpose of the study was to identify variables that are associated with pathological complete response. It is not surprising that previously reported predictive variables are confirmed: lower tumor grade, lower clinical $\mathrm{T}$ and $\mathrm{N}$ stage, higher radiation dose, and delaying surgery $>6-8$ weeks after the end of radiation. Whereas these data are valuable to better understand response to chemoradiation in general, they are not really of benefit in decision making for the individual patient. For patients who have an accepted indication for neoadjuvant therapy, the actual assessment of the response after a sufficiently long interval with clinical examination, endoscopy, and MRI will provide much more accurate information that overrides any weak prediction from baseline variables. ${ }^{10}$ For patients with smaller tumors that can be treated with surgery alone but who also have a higher chance of a complete response to chemoradiation, the prediction at primary presentation becomes more interesting. With the combination of variables obtained from clinical data, tumor biopsies, and radiological images, a good predictive model could support a more rational treatment choice that maximizes oncological and functional outcome. Another interesting finding in the paper is the selection bias that appears towards the end of the 5-year period when the pCR rate after major resections decreases from $31.9 \%$ in 2006 to $18.8 \%$ in 2011. The most logical explanation is that, despite the absence of level I evidence, surgeons have slowly accepted organ preservation by local excision or a watch-and-wait strategy as an alternative to a major rectal resection in some patients with a very good response.

An often-repeated caveat of the watch-and-wait approach is that at present our ability to assess the response is not accurate enough to exclude residual tumor and that it is therefore oncologically unsound. Although better 
diagnostic tools are always welcome, the heart of the paradigm change of organ preservation in rectal cancer involves more than a simple diagnostic improvement. It is a change in treatment concepts such as willingness to adapt the surgical plan according to the response, prolonging observation time in good responders, role of TME as salvage surgery, and expanding the role of patients in treatment choices. Of course, not all of the questions in organ preservation have been answered, and the challenge remains for how to obtain scientific evidence for the exact risks and benefits. ${ }^{11}$ Randomized trials provide the best answers for a number of clinical questions, such as the value of a radiotherapy boost or the option of chemoradiation and organ preservation versus a low anterior resection in small rectal tumors. In other clinical situations, such as patients who show a very good response after chemoradiation and patients who are facing rectal amputation, a randomized trial will be more difficult, because many of these patients express a strong preference to avoid major surgery and/or a definitive colostomy. The next best level of evidence consists of large, well-documented prospective cohort studies. Combining data of centers that practice watch-and-wait into a large database, such as the International Watch and Wait Database, provides an opportunity to study and compare real-world differences in assessment, follow-up, and outcome. ${ }^{12}$

What are we going to do with complete responses after chemoradiation of rectal cancer? I suggest that we cautiously move ahead and offer the option of organ preservation to patients in a controlled setting and combine this with providing further evidence. This can be achieved by setting up a prospective organ preservation protocol with standardized assessment and follow-up in centers that add their data to a large, multicenter database. At least initially it seems wise to concentrate organ preservation to a limited number of centers to gain sufficient expertise more quickly. When we join forces, we will obtain highquality information about the benefits and risks and we will be able maintain good oncological outcome with improved quality of life for our patients.

\section{REFERENCES}

1. Al-Sukhni E, Attwood K, Mattson DM, Gabriel E, Nurkin SJ. Predictors of pathologic complete response following neoadjuvant chemoradiotherapy for rectal cancer. Ann Surg Oncol. Accessed 14 Dec 2015.

2. Habr-Gama A, Perez RO, Nadalin W et al. Operative versus nonoperative treatment for stage 0 distal rectal cancer following chemoradiation therapy: long-term results. Ann Surg. 2004; 240(4):711-7; discussion 717-8.

3. Appelt AL, Ploen J, Harling $\mathrm{H}$ et al. High-dose chemoradiotherapy and watchful waiting for distal rectal cancer: a prospective observational study. Lancet Oncol. 2015;16(8):91927.

4. Breugom AJ, van de Velde CJ. Is it time for watchful waiting for rectal cancer? Lancet Oncol. 2015;16(8):875-6.

5. Garcia-Aguilar J, Renfro LA, Chow OS et al. Organ preservation for clinical T2N0 distal rectal cancer using neoadjuvant chemoradiotherapy and local excision (ACOSOG Z6041): results of an open-label, single-arm, multi-institutional, phase 2 trial. Lancet Oncol. 2015;16(15):1537-46.

6. Glynne-Jones R. Early rectal cancer: opening the door to change. Lancet Oncol. 2015;16(15):1449-51.

7. Renehan AG, Malcomson L, Emsley R, et al. Watch-and-wait approach versus surgical resection after chemoradiotherapy for patients with rectal cancer (the OnCoRe project): a propensityscore matched cohort analysis. Lancet Oncol. Accessed 16 Dec 2015.

8. Perez RO. Complete clinical response in rectal cancer: a turning tide. Lancet Oncol. 2016;17(2):125-6.

9. Heald RJ, Beets G, Carvalho C. Report from a consensus meeting: response to chemoradiotherapy in rectal cancer-predictor of cure and a crucial new choice for the patient: On behalf of the Champalimaud 2014 Faculty for 'Rectal cancer: when NOT to operate. Colorectal Dis. 2014;16(5):334-7.

10. Maas M, Lambregts DM, Nelemans PJ et al. Assessment of clinical complete response after chemoradiation for rectal cancer with digital rectal examination, endoscopy, and MRI: selection for organ-saving treatment. Ann Surg Oncol. 2015;22(12):387380.

11. Marijnen CA. Organ preservation in rectal cancer: have all questions been answered? Lancet Oncol. 2015;16(1):e13-22.

12. Beets GL, Figueiredo NL, Habr-Gama A, van de Velde CJ. A new paradigm for rectal cancer: organ preservation: introducing the international watch \& wait database (IWWD). Eur J Surg Oncol. 2015;41(12):1562-4. 